\title{
QUANTITATIVE ASSESSMENT OF RICE CROP DAMAGE POST TITLI CYCLONE IN SRIKAKULAM, ANDHRA PRADESH USING GEO-SPATIAL TECHNIQUES
}

\author{
G. G. Ponnurangam ${ }^{1}$, T. D. Setiyono ${ }^{2}$, A. Maunahan ${ }^{2}$, S. S. Satapathy ${ }^{1}$, E. Quicho ${ }^{2}$, L. Gatti ${ }^{3}$, G. Romuga ${ }^{2}$, C. Garcia ${ }^{2}$, P. \\ Prasadini ${ }^{4}$, M. Sunil Kumar, P. Prasuna Rani ${ }^{4}$, Ch. Kranthi Kumar ${ }^{1}$, K. J. Ramohan Reddy ${ }^{1}$, F. Holecz ${ }^{3}$ \\ ${ }^{1}$ International Rice Research Institute, Country Office, Lam, Guntur 522034, A.P. India \\ (p.ganesan, s.satapathy, k.k.challa, k.reddy)@irri.org \\ ${ }^{2}$ International Rice Research Institute, Head Quarters, DAPO Box 7777, Metro Manila 1301, Philippines s \\ (t.setiyono, a.maunahan, e.quicho, g.romuga, c.garcia)@irri.org \\ ${ }^{3}$ Sarmap, Cascine di Barico 10, Purasca 6989, Switzerland - (lgatti, fholecz)@sarmap.ch \\ ${ }^{4}$ Acharya N.G. Ranga Agricultural University, Guntur 522034, A.P., India - prabhuprasadini@rediffmail.com, (kumarsuniling, \\ prasunaranip)@gmail.com
}

Commission III, WG III/10

KEY WORDS: Synthetic Aperture Radar (SAR), Flood Inundation Mapping, Rice Crop Detection, Damage Assessment, ORYZA

\begin{abstract}
:
Mapping the extent of damage due to natural calamities remains one of the thrust areas in monitoring resource inventory through geo-spatial techniques. The effect of the cyclone 'Titli' and heavy rains during first fortnight of October 2018 in Srikakulam district, Andhra Pradesh State has been demonstrated using geo-spatial technology in terms of flood inundated rice area and corresponding yield and production loss. The pre- and post-cyclone (5 and 13 October 2018) flood inundation maps were generated using Sentinel$1 \mathrm{~A}$ and TerraSAR-X Synthetic Aperture Radar (SAR) data respectively. The pre-cyclone rice area estimates were derived from multi-temporal Sentinel-1A SAR data, while yield forecast is based on the combination of satellite observations and yield simulation using ORYZA crop growth model. An intensive ground truth data collection had been carried out for the validation of satellitederived rice area estimation of pre-cyclone event. An accuracy assessment has been carried out for district, mandal and village level. An overall accuracy of $96 \%$ with kappa coefficient 0.92 has been achieved. With the help map flood inundation and rice area maps, mandal-wise flood affected rice area and corresponding yield loss have been estimated. The post-cyclone ground truth data had been collected for quantitative assessment of crop damaged area. An overall accuracy of the flood affected rice map was $85 \%$ with kappa coefficient 0.70. It was estimated that rice crop damage assessment with SAR data indicated 53312 ha out of 205174 ha were affected and corresponding estimated yield as well as production are $0.8 \mathrm{t} / \mathrm{ha}$ and $189160 \mathrm{t}$ respectively.
\end{abstract}

\section{INTRODUCTION}

Andhra Pradesh, located in the Southeast coast of India, is vulnerable to natural disaster on account of its geo-climatic conditions with flood, droughts, cyclone that frequently affect the agricultural crop lands in this state. Appropriate decisions and planning by the government as well as the relevant stakeholders in the phase of such calamities require timely monitoring and assessment of damages in which geospatial technology can contribute. In collaboration with the Department of Agriculture, Government of Andhra Pradesh, Acharya N.G. Ranga Agricultural University (ANGRAU), and sarmap (Switzerland), the International Rice Research Institute (IRRI) embarked in initiative to establish a satellite-based rice monitoring system (SRMS) for the state of Andhra Pradesh which aims to deliver near-real time information on rice area, and yield as well as extent of damage in the case of natural disasters such as flood (including such abiotic adversary induced by cyclone) and drought.

Strong cyclonic storm poses threat to coastal agriculture in Andhra Pradesh due to heavy rainfall and high wind spend associated with the storms leading to considerable economic losses to farmers. Due to its synoptic view, remote sensing along with GIS and GPS techniques can support quantitative assessment of damages due to such natural calamities. In particular, Synthetic Aperture Radar (SAR) remote sensing plays a crucial role due to its independent weather capability, day and night observation, sensitive to target dielectric and geometric properties and penetration capabilities.

Indeed, SAR is very useful for flood inundation mapping due to low backscatter sensitivity of surface water. Thus, it is helpful for assessing flood affected agricultural crop lands. Haldar et al. (2016) demonstrated the assessment of impact of 'Phailin' cyclone on rice in Odisha, India. However, the corresponding yield and production loss estimation has not been investigated. This paper demonstrates the quantitative assessment of rice crop damaged area and yield as well as production loss in Srikakulam district of Andhra Pradesh as it embraced the impact of cyclone 'Titli' during the end of first fortnight of October 2018. The paper is organized as follows: The description about the study area and datasets used for this study are given section II. Section III describes the various satellite data processing steps for flood inundation mapping, rice crop detection and rice yield forecast estimation using ORYZA crop growth model and MapScape-RICE and RICE-YES software. The results obtained and damage assessment is discussed in section IV.

\section{STUDY AREA AND DATA SETS SUED}

\subsection{Study Site}

The study area focuses on the major rice growing mandals in Nagavalli and Vamsadhara river basins as well as coastal mandals in Srikakulam district, Andhra Pradesh. The total 
geographic area of Srikakulam district is 5837 sq.km. The study site exhibits relatively undulated terrain. This study area exhibits a wide variety of land cover types such as forest, waterbodies, settlements and various agriculture crops. The percentage of land cover for agriculture, built-up, forest, wasteland, waterbody and wetlands are $70.89 \%, 2.17 \%$, $11.39 \%, 8.34 \%, 5.80 \%$ and $1.4 \%$ respectively. As far as agriculture crop concerned, paddy is the main crop grown in the district with the coverage of 191000 ha, followed by Groundnut (35000 ha). Other crops cultivated in the district include Sugarcane, Bajra, Sesamum and Pulses etc. Plantation crops include Cashew, Tapioca, Mango, Banana etc.

\subsection{Satellite and ground data observations}

Time series of dual-polarimetric, (VH/VV) C-band Sentinel-1A SAR data over the Srikakulam district from 7 June to 23 September 2018 are used for rice crop area estimation and yield forecasting. The time series comprises 17 Ground Range Detected (GRD) SAR data sets with an incidence angle ranges around from $30^{\circ}$ to $46^{\circ}$ and a spatial resolution of $20 \mathrm{~m}$. Intensive ground measurements for $\operatorname{rice}(\mathrm{R})$ and non-rice $(\mathrm{nR})$ points have been collected during the beginning of the season and peak season for calibration of decision rule-based rice classifier and validation respectively. The commercial X-band TerrsaSAR-X SAR (HH-polarization) data with 16.7 x $18.6 \mathrm{~m}$ (range $x$ azimuth) resolution and incident angle of $46^{\circ}$ was acquired on 13 October 2018 for flood inundation mapping during post 'Titli' cyclone event in Srikakulam district. In order to assess and validate the rice crop damage, a separate ground data collection had been carried out during 19-21 October 2018.

For yield forecast estimation, the combination of satellite observations and yield simulation using ORYZA crop growth model, taking into account weather, soil, and site specific agronomic management information have been utilized. Inseason weather data were obtained from local source (APSDPS website) and NASA power data for solar radiation (Chandler et al., 2014) whereas forecasted weather data for days to come during the growing season were obtained by generating daily weather forecast using analog approach historical weather data based on NASA power for solar radiation, NCDC GSOD for temperature data (NCDC, 2017), and CHIRPS for rainfall data (Funk et al., 2015), considering seasonal outlook scenarios with normal projection for temperature and above normal for rainfall. Soil data were obtained from World Inventory of Soil Emission potential (WISE) database (Gijsman et al., 2007) and Harmonized World Soil Database (HWSD) (FAO, 2012). Site specific agronomic management information used in the model were gathered by collecting information from the local farmers.

\section{METHODOLGY}

SAR data processing for both rice crop area estimation, yield forecasting and flood inundation mapping have been done using MapScape-RICE software developed by SARMAP (Nelson et al., 2014). For yield forecasting, RICE-YES, developed by IRRI, provides interface between MapScape-RICE and ORYZA crop growth model (Setiyono et al., 2018). ORYZA crop growth model is the driver of weather and processed based yield estimation (Bouman et al., 2001).

\subsection{Rice Area Estimation}

The pre-processing steps in MapScape-RICE software for multi-season rice area classification using multi-temporal SAR data sets involve automatic grouping of the SAR data belonging to the same acquisition geometry, slant range strip-wise mosaicking, multi-looking, multi-temporal image coregistration, time-series speckle filtering, terrain geocoding and Anisotropic Non-Linear Diffusion (ANLD) filtering (for smoothening the homogeneous area). All these processing steps are a fully automated processing chain in MapScape-RICE software which converts the Sentinel-1 GRD time series SAR data into terrain-geocoded backscattering $\left(\sigma^{0}\right)$ values. The multitemporal, decision rule-based rice classification algorithm was then applied to ANLD filtered $\sigma^{0}$ images for multi-season rice crop detection (Nelson et al., 2014) and date of transplantation based on lowest backscattered $\left(\sigma^{0}\right)$ values. Similarly, flood inundated map was generated in MapScape RICE using Sentinel-1A C-band (pre-cyclone) and TerraSAR-X X-band (post-cyclone) SAR data sets along with the digital elevation model. Flood mapping is based on low backscatter threshold decrement between pre- and post-cyclone event. TerraSAR-X data was resampled to $20 \mathrm{~m}$ resolution during geo-coding process.

\subsection{Yield Forecast Estimation}

Pre-harvest yield forecast was generated using ORYZA crop growth model and RICE-YES software, along with local weather, soil, varietal, and crop management information in Srikakulam (Setiyono et al., 2017; 2018). During the 'Titli' cyclone event, rice crop stages in Srikakulam district ranges from flowering to maturity with some fields ready to be harvested in 2 week time. Rice classified image was then used a mask to identify the flood inundated rice area and the corresponding yield and production loss estimation.

\section{RESULTS AND DISCUSSIONS}

\subsection{Validation of Rice Products}

Rice area and start of season maps generated from multitemporal SAR data and MapScape-RICE are shown in Figs. 13. As of 10 October 2018, satellite imageries estimated a total of 205174 ha rice area had been planted in Srikakulam district in kharif 2018. The rice area map along with ground validation points for Srikakulam district is shown in Fig. 1.

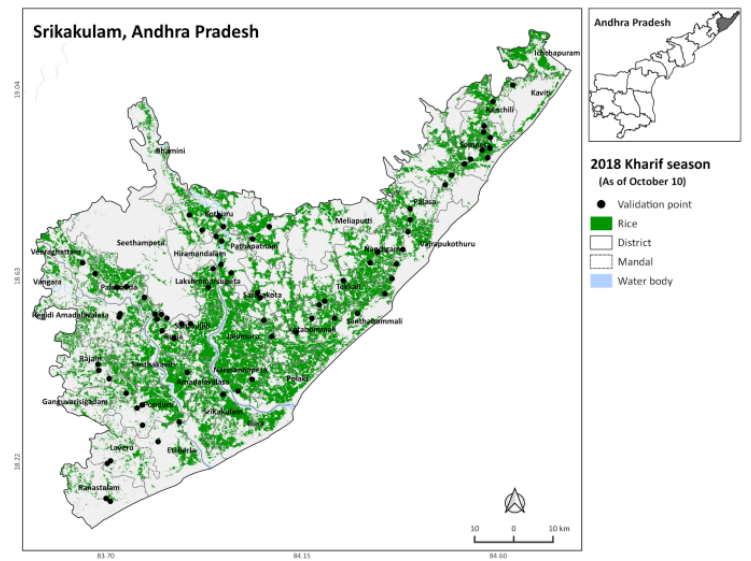

Figure 1. Rice area estimates in Srikakulam district with ground truth validation points, 2018 kharif, 10 October 2018. 


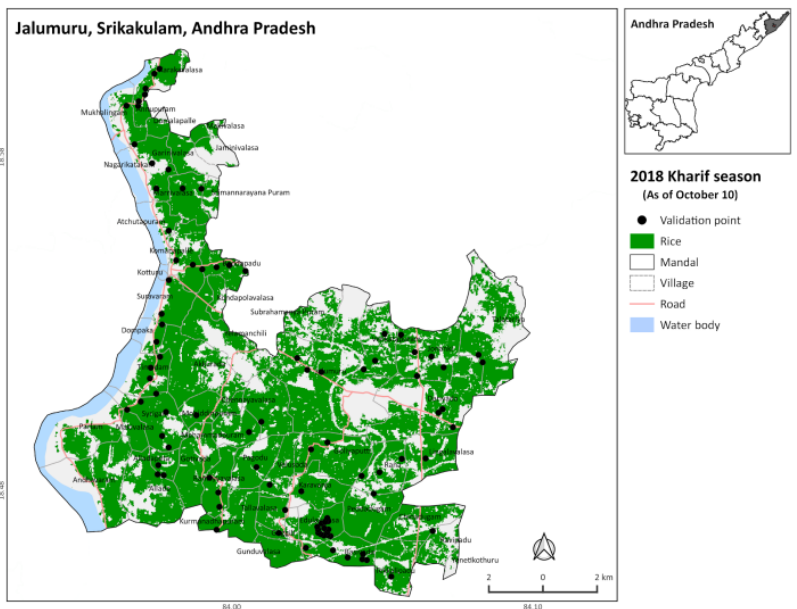

Figure 2. Rice area estimates in Jalumuru mandal, Srikakulam district with validation points, 2018 kharif, 10 October 2018.

An accuracy assessment of the satellite-derived rice estimates was carried out, based on the confusion matrix approach (Congalton, 2001) using RnR ground truth data and summarized in Table 1. At district level, the rice area estimates have an overall accuracy of $96 \%$ with kappa index of 0.92 .

\begin{tabular}{|lccccc|}
\hline $\begin{array}{l}\text { Name of Administrative Entity } \\
\text { (District, Mandal and Villages) }\end{array}$ & $\begin{array}{c}\text { Valida } \\
\text { tion } \\
\text { Points }\end{array}$ & $\begin{array}{c}\text { Average } \\
\text { Accuracy } \\
\text { (\%) }\end{array}$ & $\begin{array}{c}\text { Average } \\
\text { Reliability } \\
\text { (\%) }\end{array}$ & $\begin{array}{c}\text { Overall } \\
\text { Accuracy } \\
\text { (\%) }\end{array}$ & $\begin{array}{c}\text { Kappa } \\
\text { Index }\end{array}$ \\
\hline $\begin{array}{l}\text { District Level } \\
\text { Srikakulam } \\
\text { Mandal Level }\end{array}$ & 76 & 78.6 & 97.9 & 96.1 & 0.92 \\
$\begin{array}{l}\text { Srikakulam, Jalmuru } \\
\text { Village Level } \\
\text { Srikakulam, Jalmuru, Jalmur }\end{array}$ & 33 & 983 & 90.0 & 97.0 & 0.94 \\
\hline
\end{tabular}

Table 1. Summary of validation points and accuracy assessment of satellite-based rice area estimates in Srikakulam District.

In order to assess the rice product at mandal and village level, an intensive ground truth data has been collected at mandal and village level in a selected mandal. This village and mandal within the district has been selected based on the size of the area of mandal and village (within the selected mandal) which covers major rice and non-rice area. In Srikakulam district, Jalumuru village and Jalumuru mandal has been selected for ground truth data collection and for the accuracy assessment at mandal as well as village level. The mandal level rice map for Jalumuru mandal is shown in Fig. 2. The summary of accuracy assessment for the mandal level and village level rice estimates has been presented in Table 1. An overall accuracy for mandal and village level is $99 \%$ and $97 \%$ respectively with kappa coefficient 0.98 and 0.94 respectively. The high kappa coefficient values of village and mandal level assessment indicates that the satellite-derived rice estimates in good agreement with the ground data.

Start of season map derived using the lowest backscatter (dB) signal of SAR data and shown in Fig. 3. It is observed from Fig. 3 that majority of rice were transplanted around 6 August 2018 and followed by 13 July 2018 and 18 August 2018. Relatively less rice was transplanted around 18 July 2018 followed by 6 July 2018 and 12 June 2018 which includes some early planted rice areas in the upland area of Vamsadhara river basin.

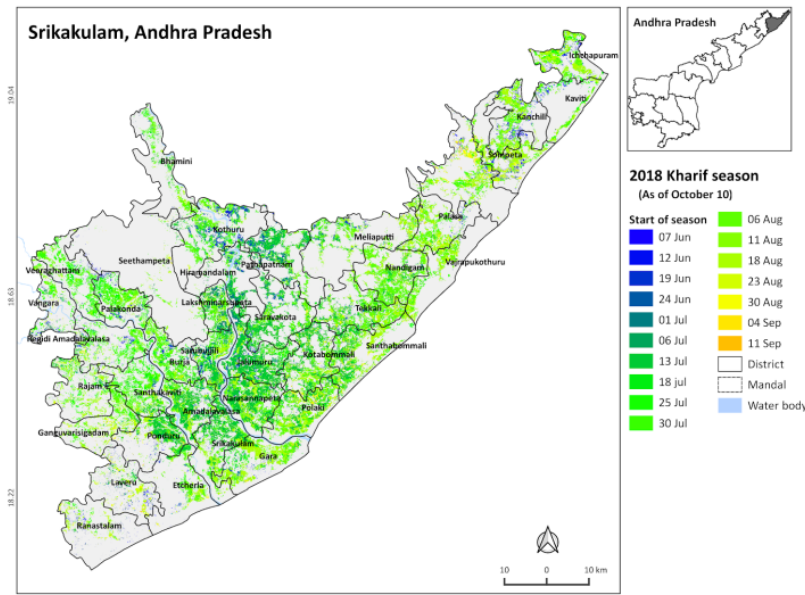

Figure 3. Start of season of rice cultivation in Srikakulam district during kharif 2018.

In addition to accuracy assessment, satellite-based rice area estimates were compared against the traditional DoA/DES statistics data and as well the newly established digital real time data called "e-panta". At district level, the DoA/DES total planted area is around 209000 ha while SRMS estimated area is 203000 ha. An overall 3\% deviation (6000 ha) between DoAreported and SRMS estimated area has been observed for kharif 2018. Similarly, mandal level comparison includes both underand over-estimation as compared to DoA-reported area statistics and depicted in Fig. 4. An Average agreement of $97 \%$ between the two datasets were observed as of 11 September 2018.

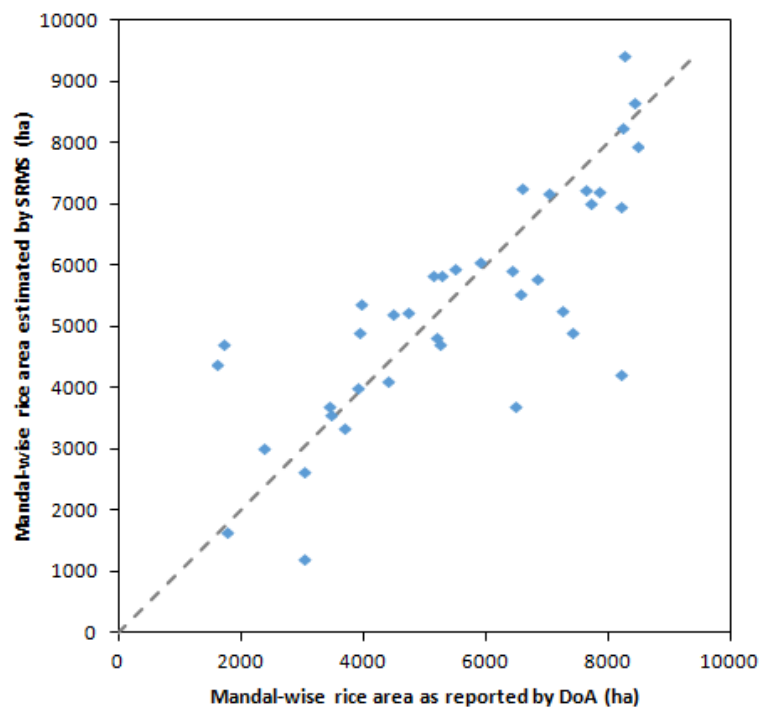

Figure 4. Comparison of mandal-wise rice area estimates with rice area from DoA, 2018 kharif, 11 September 2018.

Indeed, Ranastalam and Laveru mandals show an overestimation of approximately 3000 ha, while Meliaputti and Seethampeta mandals are under-estimated. In order to ensure the village level accuracy of rice area map, the village level crop information downloaded from e-panta website and the area statistics were compared and summarized in Table 2. 


\begin{tabular}{lccccc}
\hline $\begin{array}{l}\text { Name of } \\
\text { Administrative } \\
\text { Entity }\end{array}$ & $\begin{array}{c}\text { Validation } \\
\text { Points }\end{array}$ & $\begin{array}{c}\text { Average } \\
\text { Accuracy } \\
\mathbf{( \% )}\end{array}$ & $\begin{array}{c}\text { Average } \\
\text { Reliability } \\
\mathbf{( \% )}\end{array}$ & $\begin{array}{c}\text { Overall } \\
\text { Accuracy } \\
\mathbf{( \% )}\end{array}$ & $\begin{array}{c}\text { Kappa } \\
\text { Index }\end{array}$ \\
\hline Srikakulam & 119 & 93.0 & 56.0 & 87.0 & 0.73 \\
\hline
\end{tabular}

Table 2. Summary of accuracy assessment of satellite-based rice area with e-panta data.

A total of 119 validation points have been used for the accuracy assessment. An overall accuracy for the district level is $87 \%$ with kappa coefficient 0.73 . However, this is the results from an initial investigation using the data downloaded for limited mandals. Thus, further investigation has to be carried out to understand the usefulness and utilization of e-panta data for village level accuracy assessment.

\subsection{Pre-harvest yield forecast estimation}

The estimated pre-harvest yield map for district and mandal is depicted in Figs. 5 and 6. In Srikakulam, the average yield at the mandal level was recorded at $2.94 \mathrm{t} / \mathrm{ha}$ (with yield that range from $1.95 \mathrm{t} / \mathrm{ha}$ to $4.00 \mathrm{t} / \mathrm{ha}$ ) while the average on the village level was at $3.01 \mathrm{t} / \mathrm{ha}$.

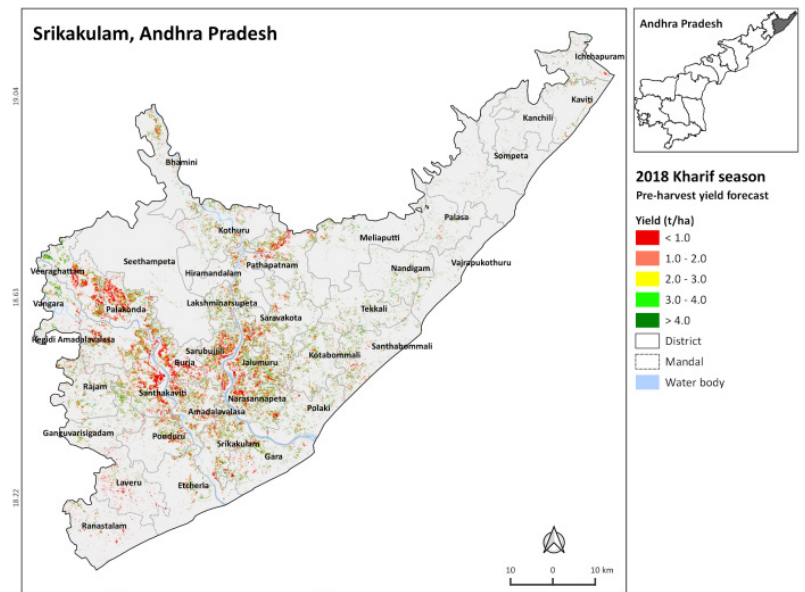

Figure 5. Pre-harvest yield forecast in Srikakulam district, 2018 kharif, 3 October 2018.

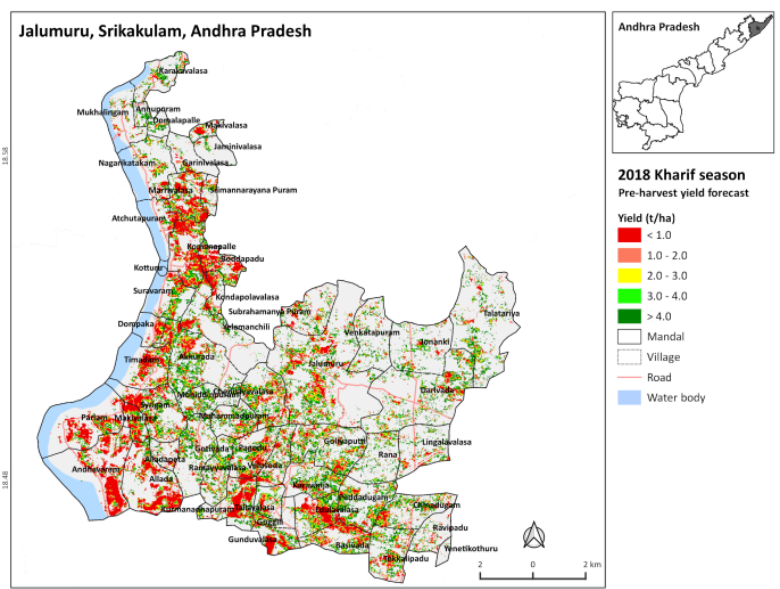

Figure 6. Pre-harvest yield forecast in Jalumuru mandal, Srikakulam district, 2018 kharif, 3 October 2018.

\subsection{Rice Crop Damage Assessment Post Cyclone 'Titli'}

On the early hours of 11 October 2018, cyclone 'Titli', which was categorized by India Meteorology Department (IMD) as very severe cyclonic storm, made landfall on coastal area of Andhra Pradesh near Palasa, Srikakulam. The cyclone track and relevant information about this cyclone has been gathered from Global Disaster Alert and Coordination System (http://www.gdacs.org/). The nearest timing of Sentinel-1 satellite pass over Srikakulam were 07 October 2018 (before the cyclone) and 29 October 2018 (18 days after cyclone 'Titli' made the landfall) and therefore it was not possible to use Sentinel-1 SAR data to immediate impact of this cyclone. As no non-commercial SAR data is available, the commercial X-Band TerraSAR-X scanSAR mode HH-polarization SAR data has been programmed and acquired on 13 October 2018. The resulting maps of flood inundation post cyclone 'Titli' along with ground truth points is shown in Fig. 7. Inundation assessment with SAR data on 13 October 2018 indicated 53312 or $26 \%$ of estimated rice area were affected. Heavy loss of rice production was expected considering the crop stage was at flowering or beyond (including grain filling). The same was also detected by the SAR based rice monitoring system.

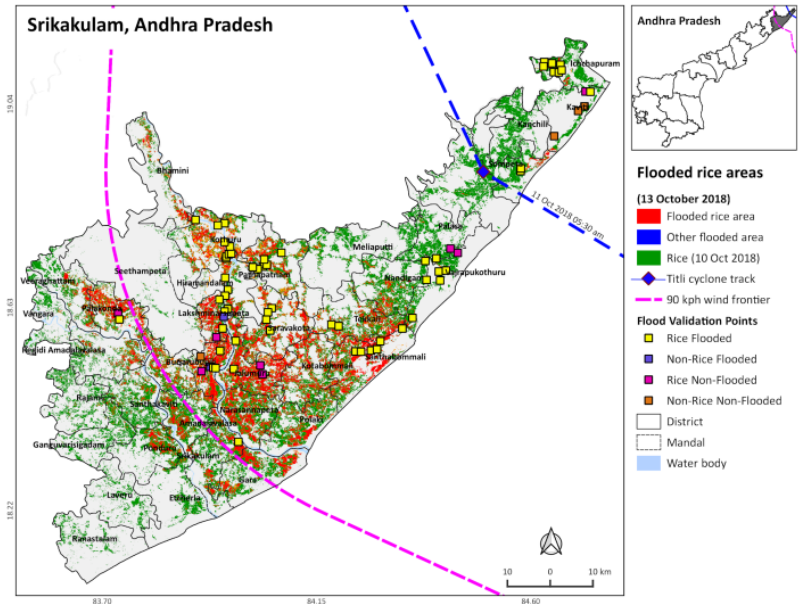

Figure 7. Rice area affected by cyclone 'Titli' with cyclone track and validation points on 13 October 2018.

An accuracy assessment of the flood maps has been carried out using 40 ground observation points collected during 19-21 October 2018 and the results are tabulated in Table 3. An overall accuracy is $85 \%$ with kappa coefficient 0.70 . Likewise, observations of extent of damage on rice crop including the effect fully and non-complete submergence and lodging due to strong gust from the cyclone were recorded with geo-tagged photographs. Based on these ground observations and photos (see Fig. 8), a major flood damaged information for surrounding observation point were manually digitized to account for the actual crop damage and yield loss.

\begin{tabular}{lccccc}
\hline $\begin{array}{l}\text { Name of } \\
\text { Administrative } \\
\text { Entity }\end{array}$ & $\begin{array}{c}\text { Validation } \\
\text { Points }\end{array}$ & $\begin{array}{c}\text { Average } \\
\text { Accuracy } \\
(\mathbf{\%})\end{array}$ & $\begin{array}{c}\text { Average } \\
\text { Reliability } \\
(\mathbf{\%})\end{array}$ & $\begin{array}{c}\text { Overall } \\
\text { Accuracy } \\
(\mathbf{\%})\end{array}$ & $\begin{array}{c}\text { Kappa } \\
\text { Index }\end{array}$ \\
\hline Srikakulam & 40 & 81.2 & 81.2 & 85 & 0.70 \\
\hline \multicolumn{2}{r}{ Table 3. Summary of flood validation points and accuracy }
\end{tabular}

assessment of Satellite based rice area map for kharif 2018.

Based on this exercise, it was estimated that the extent of damage based on field visit was roughly $30 \%$ additional to the area mapped as fully submerged by 13 October 2018, and thus 
providing overall estimated damage extent at 69306 ha or $33.8 \%$ of total rice area in Srikakulam.
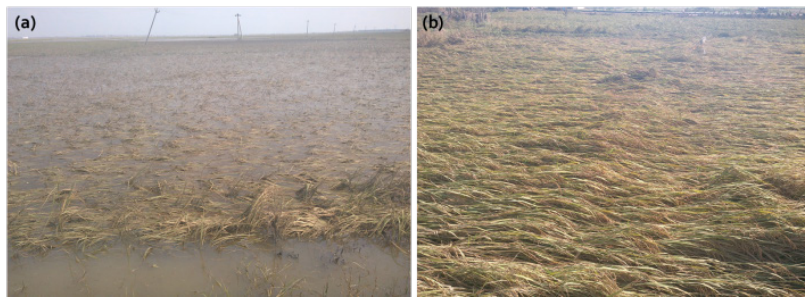

Figure 8. Field photographs of rice crop damage post cyclone 'Titli' (a) Pundi, Santabommali mandal on 16 October 2018 and

(b) in Dasupuram, Pathapatnam mandal on 18 October 2018.

Moreover, with the same ground observation, the flood-affected rice map was categorized into four classes namely Slightly damaged $(<25 \%$ expected loss), moderately damaged $(25 \%$ $50 \%$ expected loss), severely damaged (50\%-75\% expected loss) and totally damaged (100\%expected loss) and shown in Figs. 9 and 10.

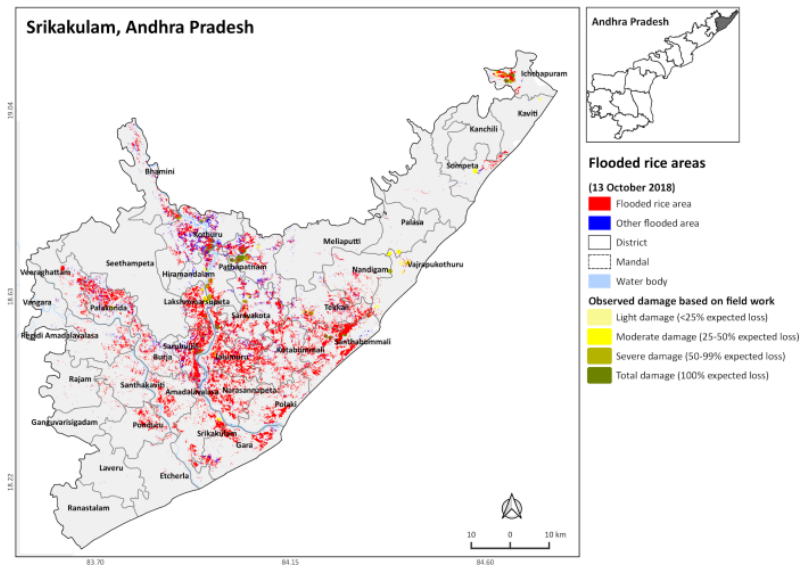

Figure 9. The observed rice crop damaged area based on field work in Srikakulam district on 13 October 2018.

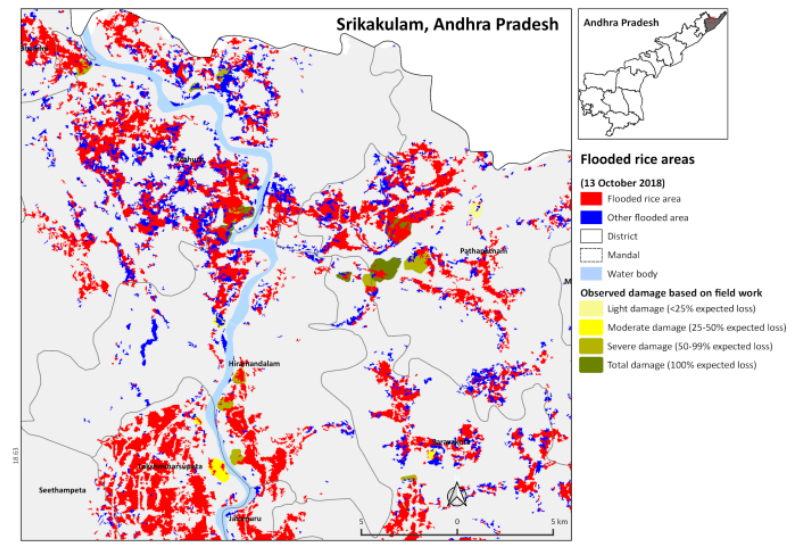

Figure 10. The observed rice crop damaged area in Jalumuru and Lakshminarsupeta mandals on 13 October 2018.

Similarly, pre-harvest yield forecast, which was generated using SAR data and ORYZA crop growth model, maps have been used a mask on flood inundated map for mandal wise-wise yield and production loss estimation due to cyclone Titli were also generated. By considering only detected inundation area, the overall estimated yield loss was $0.8 \mathrm{t} / \mathrm{ha}$, whereas estimated production loss was round $189160 \mathrm{t}(23 \%)$. However, with consideration of damage beyond inundated area (partial submergence and effect of storm surge), the estimated yield loss is $1.06 \mathrm{t} / \mathrm{ha}$, while estimated production loss is $245908 \mathrm{t}(33 \%)$.

As a next step, with the help of ground truth data, analysis of various multi-temporal features and signatures from both optical and SAR data are under progress to detect the extent of crop damaged area. Thus, multi-temporal (3 or 4 acquisitions) signatures will be analysed for mapping of crop failure and survived fields and it is planned to conduct ground truth data for validation of such crop failure/survived maps. Hence, more quantitative damage assessment could be possible using satellite-derived multi-temporal parameters.

\section{ACKNOWLEDGEMENTS}

Funding for this work was provided by Govt. of A.P. and the International Rice Research Institute (IRRI). The project also benefits from the technical support of Andhra Pradesh Department of Economics and Statistics (A.P. DES) and Andhra Pradesh Space Applications Centre (APSAC).

\section{REFERENCES}

Andhra Pradesh State Development Planning Society (APSDPS).http://www.apsdps.gov.in/.

Bouman, B. A. M., Kropff, M., Tuong, T. P., Wopereis, M. C. S., Ten Berge, H. and van Laar. H. 2001. ORYZA2000: Modeling Lowland Rice. Los Baños, Philippines: International Rice Research Institute, and Wageningen, Netherlands: Wageningen University and Research Centre.

Chandler, W.S., Whitlock, C.H. and Stackhouse P.W. 2014. NASA Climatological Data for Renewable Energy Assessment. ASME Journal of Solar Energy Engineering, 126, pp. 945-949. https://power.larc.nasa.gov/.

Congalton, R.G. 2001. Accuracy assessment and validation of remotely sense and other spatial information. International Journal of Wildland Fire, 10, pp. 321-328.

FAO IIASA ISRIC ISSCAS JRC. 2012. Harmonized World Soil Database (Version 1.2). Rome, Italy: FAO and Laxenburg, Austria: IIASA.

Funk, C., Peterson, P., Landsfeld, M., Pedreros, D., Verdin, J., Shukla, S., Husak, G. et al. 2015. "The climate hazards infrared precipitation with stations - a new environmental record for monitoring extremes". Scientific Data 2, 150066. doi: 10.1038/sdata.2015.66.

Gijsman, A.J., Thornton, P.K. and Hoogenboom. G., 2007. Using the WISE database to parameterize soil inputs for crop simulation models. Computers and Electronics in Agriculture 56 , pp. $85-100$.

Haldar, D., Nigam, R., Patnaik, C., Dutta, S., Bhattacharya, B. 2016. Remote sensing-based assessment of impact of Phailin cyclone on rice in Odisha, India, Paddy and water environment, 14(4), pp. 451-461.

NCDC NESDIS NOAA. 2017. Global Surface Summary of the Day (GSOD). U.S. Department of Commerce. http://www7.ncdc.noaa.gov/CDO/cdoselect.cmd. Accessed on June 11, 2017. 
Nelson, A., Setiyono, T. Rala, A. B., Quicho, E. D., Raviz, J. V., Abonete, P. J., Maunahan, A., Garcia, C. A., Bhatti, H. Z. M., Villano, L. S., et al. 2014. Toward an operational SAR-based rice monitoring system in Asia: Examples from 13 demonstration sites across Asia in the RIICE project. Remote Sensing, 6, pp. 10773-10812.

Setiyono, T. D., Quicho, E. D., Romuga, G. C. 2017. Rice Yield Estimation (Rice-YES) User Manual; International Rice Research Institute: Los Baños, Philippines.

Setiyono, T.D., Quicho, E. D., Holecz, F., Khan, N. I., Romuga, G., Maunahan, A., Garcia, C., Rala, A., Raviz, J., Collivignarelli, F., Gatti, L., Barbieri, M., Phuong, D. M., Minh, V. Q., Vo, Q. T., Intrman, A., Rakwatin, P., Sothy, M., Veasna, T., Pazhanivelan, S., Mabalay, M.R. 2018. Rice yield estimation using synthetic aperture radar (SAR) and the ORYZA crop growth model: development and application of the system in South and South-east Asian countries. International Journal of Remote Sensing. DOI: 10.1080/01431161.2018.1547457. 